\title{
Risk Factors Associated With Medication Errors Among Patients Suffering From Chronic Disorders
}

\section{OPEN ACCESS}

Edited by:

Mirjana Ratko Jovanovic

University of Kragujevac, Serbia

Reviewed by:

Tissa Wijeratne,

The University of Melbourne, Australia Mohamed Izham Mohamed Ibrahim,

Qatar University, Qatar

Sulaiman Mouselli, Arab International University, Syria

Guvenc Kockaya, ECONiX Research, Analysis and Consultancy Plc., Istanbul, Turkey Mohsen Shams,

Yasuj University of Medical Sciences, Iran

*Correspondence: Anees ur Rehman aneesurrehmanr90@gmail.com

Specialty section:

This article was submitted to Health Economics,

a section of the journal

Frontiers in Public Health

Received: 30 January 2020 Accepted: 13 October 2020 Published: 19 November 2020

Citation:

Rasool MF, Rehman Au, Imran I, Abbas S, Shah S, Abbas G, Khan I, Shakeel S, Ahmad Hassali MA and Hayat K (2020) Risk Factors Associated With Medication Errors Among Patients Suffering From Chronic Disorders.

Front. Public Health 8:531038. doi: 10.3389/fpubh.2020.531038

\author{
Muhammad Fawad Rasool ${ }^{1}$, Anees ur Rehman ${ }^{1,2 *}$, Imran Imran ${ }^{3}$, Sameen Abbas ${ }^{4}$, \\ Shahid Shah ${ }^{5}$, Ghulam Abbas ${ }^{6}$, Irfanullah Khan ${ }^{2}$, Sadia Shakeel ${ }^{2,7}$, \\ Mohamed Azmi Ahmad Hassali ${ }^{2}$ and Khezar Hayat ${ }^{8}$
}

\begin{abstract}
'Department of Pharmacy Practice, Faculty of Pharmacy, Bahauddin Zakariya University, Multan, Pakistan, ${ }^{2}$ Department of Clinical Pharmacy, School of Pharmaceutical Sciences, University Sains Malaysia, Penang, Malaysia, ${ }^{3}$ Department of Pharmacology, Faculty of Pharmacy, Bahauddin Zakariya University, Multan, Pakistan, ${ }^{4}$ Department of Pharmacy, Quaid e Azam University, Islamabad, Pakistan, ${ }^{5}$ Department of Pharmacy Practice, Faculty of Pharmaceutical Sciences, Government College University, Faisalabad, Pakistan, ${ }^{6}$ Department of Pharmaceutics, Faculty of Pharmaceutical Sciences, Government College University, Faisalabad, Pakistan, ${ }^{7}$ Department of Pharmacy Practice, Dow University of Health Sciences, Karachi, Pakistan, ${ }^{8}$ Institute of Pharmaceutical Sciences, University of Veterinary and Animal Sciences, Lahore, Pakistan
\end{abstract}

Introduction: Medication error is unintentional and can be reduced by reducing the risk factors. Patients suffering from chronic diseases are at an increased risk of medication errors.

Objective: This work aims to assess the risk factors associated with medication errors among patients suffering from chronic disorders in hospitals of South Punjab, Pakistan.

Methodology: Multiple logistic regression analysis was used to assess the impact of different risk factors on the prevalence of medication errors in patients suffering from chronic diseases.

Results: A greater risk for the occurrence of medication errors was associated with age $\geq 60$ years (odds ratio, $\mathrm{OR}=1.9 ; 95 \% \mathrm{Cl}=1.3-3.1 ; p=0.001$ ), overburdened healthcare system $(\mathrm{OR}=2.2 ; 95 \% \mathrm{Cl}=1.64-3.56 ; p<0.000)$, number of prescribed drugs $\geq 5(\mathrm{OR}=1.74 ; 95 \% \mathrm{Cl}=1.02-2.64 ; p<0.000)$, comorbidities $(\mathrm{OR}=2.6 ; 95 \% \mathrm{Cl}=1.72-3.6 ; p=0.003)$, Charlson comorbidity index (OR = $1.31 ; 95 \% \mathrm{Cl}=0.49-1.84 ; p=0.004)$, and multiple prescribers to one patient $(\mathrm{OR}=1.12 ; 95 \% \mathrm{Cl}=0.64-1.76 ; p=0.001)$.

Conclusion: Older age, overburdened healthcare system, number of prescribed drugs, comorbidities, Charlson comorbidity index, and multiple prescribers to one patient are significant risk factors for the occurrence of medication errors.

Keywords: medication errors, drug-drug interactions, inappropriate prescribing, chronic diseases, risk factors

\section{INTRODUCTION}

A medication error may be defined as "failure in drug therapy that may result in harmful effects to patients." It is a serious concern especially in low- to middle-income countries and can result in an increased risk of drug-drug interactions, elevate the frequency of hospital admissions and outpatient visits, prolong the length of hospital stay, increase the management cost, and elevate the mortality risk (1-3). Medication errors affect seven million patients annually and result in $\sim 3.5$ 
million doctor office visits and one million emergency department visits each year. According to the Florida Health Care Coalition, around 500,000 medication errors have been estimated daily in America. It is the third leading cause of outpatient visits after cardiovascular diseases and cancer (4). In the United States of America, more people die due to medication errors than traffic accidents, auto-immunodeficiency syndrome, or breast cancer $(5,6)$. Medication-related errors are responsible for $\sim 5$ to $41.3 \%$ of all hospital admissions and $22 \%$ readmissions after discharge worldwide (7).

Medication errors result in substantial economic burden on patients and the healthcare system due to an increase in the cost of treatment (8). The economic burden due to inappropriate prescribing is preventable, and controlling medication errors can result in substantial relief to the healthcare system (9). In the USA, the economic burden due to medication errors was reduced from US\$ 177.4 billion in 2001 to US\$ 21 billion in 2014 due to the implementation of effective strategies to control medication errors $(3,6)$. In the UK, before the establishment of a "system for reporting and preventing errors" and the National Patient Safety Agency (NPSA), 850,000 adverse events were reported every year, which result in a huge economic burden of $£ 2$ billion per year due to additional hospital admissions (10). The establishment of a "reporting system" and the NPSA resulted in $40 \%$ reduction in medication errors by collecting data on adverse events and finding and implementing solutions to reduce them (11).

Different studies reported 5.4 to $66 \%$ medication errors in prescribed therapy in outpatients and hospital-admitted patients $(12-14)$. The difference in percentage of the medication errors in different studies is due to the characteristics of patients, study environment, study settings, methods utilized for assessing and classifying the errors, and prescribing practice. The risk of medication errors (having an unnecessary drug, a non-optimal drug, or a non-optimal dose) increases with the increase in the number of drugs, comorbidities, multiple prescribers, and older age $(8,15)$. The risk of incidence of medication errors increased up to $30 \%$ in patients who received five or more drugs and $38 \%$ in patients with age 75 years or older (16). The medication-related admissions were almost double in older patients (65 years or above) as compared to the younger ones (17).

Chronic diseases cause substantial economic burden and are major causes of morbidity and mortality (18-20). Two-third of the chronic disease patients are older than 60 years, suffer from different comorbidities, and are on polypharmacy (five or more drugs) (21). Older age, multiple comorbidities, and polypharmacy increases the risk of medication errors in chronic disease patients $(21,22)$. Moreover, in low- to middle-income countries like Pakistan, inappropriate prescribing, overburdened healthcare system, lack of disease surveillance system, shortage of healthcare staff, and absence of a clinical pharmacist in most of the settings are additional risk factors for medication errors (23).

Finding the factors associated with medication errors and effective strategies to prevent errors can help healthcare professionals to identify and manage medication errors. It can also reduce the economic and humanistic burden due to medication errors. Few studies assessed the relationship between medication errors and specific factors such as patient age, number of prescribers, frequency of hospitalization, length of hospital stay, cost of hospitalization, mortality rate, number of drugs prescribed, and review of prescription by a pharmacist or specialist (24-27). Moreover, data on medication errors are mostly available from hospitalized patients $(15,28)$. To the best of our knowledge, no study assessed the incidence and causes of medication errors in chronic disease patients visiting outpatient clinics for regular follow-up. Thus, the objective of the present study was to assess the prevalence and the risk factors associated with medication errors among patients suffering from chronic disorders in hospitals of South Punjab, Pakistan.

\section{METHODOLOGY}

\section{Study Design}

This study was a cross-sectional, observational, prospective one that included 803 patients from outpatient medical wards of 17 public and private hospitals (teaching and general hospitals) in different areas of South Punjab, Pakistan. The hospitals were included from all regions to obtain a representative sample. Purposeful sampling was done by including 45 patients from each hospital. Patients were included in the study if they had any disease listed in the Charlson comorbidity index (CCI), visiting outpatient for routine follow-up, prescribed with at least two drugs, age above 20 years, and with available medical records. Patients with diseases other than listed in CCI were excluded. Systematic random sampling method was used to avoid biases. Every third patient visiting the outpatient clinic was invited to participate in the study. The study protocol was approved by the Research and Ethics committee of the Faculty of Pharmacy, Bahauddin Zakariya University, and the concerned hospitals (registration no. Bzbp-18-4207). Written informed consent was obtained from all the participants.

\section{Data Collection}

A self-developed questionnaire was used to collect the patients' demographic data, socioeconomic status, clinical condition, diagnosis, names, number and doses of prescribed medicines, self-medication, if any, route of administration, appropriate drug selection, drug-disease interaction, and drug-drug interactions. The data collection form was filled after physician consultation. Medication errors were defined as inappropriate dose (dosage too low or too high), invalid indication (drug prescribed without clinical indication), drug duplication (multiple drugs for the same condition), inappropriate dosing frequency (too short or too long dosing frequency), longer duration of drug therapy than recommended, and drug-drug interactions (combination in the prescription which is prohibited or may cause harm to the patient) (29). A patient utilizing five or more medicines was considered to be a polypharmacy patient (30). The comorbidities were scored using the CCI scale (31). Overburdened was considered to check 20 or more patients in an hour (32). Data collection was done during December 2017 to August 2018 by three graduating class pharmacy students. 


\section{Drug-Drug Interaction Software}

For identification of medication errors, Pharmacotherapy: a pathophysiologic approach, 7th edition, Lexicomp Drug Information Handbook, 22nd edition, Harrison's principles of internal medicine, 17th edition, and Applied therapeutics: the clinical use of drugs, Uptodate ${ }^{\circledR} 2009$, were used. The possible potential hazardous combinations of drugs were evaluated using a drug interaction software, Micromedex ${ }^{\circledR}$ (Thomson Reuters Healthcare Inc., Greenwood Village, CO, USA) (33). For fixed drug combinations, each active ingredient was treated separately. All drugs in a prescription were added one by one in the software. The software output displays all the possible interacting combination(s) in a prescription and also provides information about the possible adverse effects of an interaction. Micromedex classifies the interactions as contraindicated (the drug pair is strictly prohibited and may be life-threatening), major (have a risk of any organ damage), moderate (require a change in therapy and/or monitoring), and minor (cause increased side effects and can be avoided by adjusting the dose) drug-drug interactions (34). All the errors were reviewed by the hospital physician and clinical pharmacist.

\section{DATA ANALYSIS}

Frequencies and percentages were reported for categorical variables, and mean and standard deviation were reported for continuous variables. Normality of the data was checked using Shapiro-Wilk test of normality. To assess the face validity, a committee of experts including two academician, two medical practitioners, and a clinical pharmacist critically reviewed the questionnaire. Internal consistency of the questionnaire was assessed based on the value of Cronbach's alpha coefficient. Internal consistency is considered as excellent if Cronbach's $\alpha$ is $\geq 0.9$, strong if Cronbach's $\alpha$ is $\geq 0.8$, acceptable if Cronbach's $\alpha$ is $\geq 0.7$, and reasonable if Cronbach's $\alpha$ is $\geq 0.6$ (35). Univariate and multivariate logistic regression analyses were used to assess the impact of age $\geq 60$ years, overburdened healthcare system, polypharmacy, number of comorbidities, CCI score, prescription by a specialist, trainee practitioner, multiple prescribers to one patient, presence of previous medical record, review of prescription by a clinical pharmacist, and use of online software in prescription generation on the prevalence of medication errors in patients suffering from chronic diseases. Initially, a univariate analysis was performed, and variables with univariate $p<0.02$ were included in the multiple regression model. Odd ratios were used to assess the influence of different risk factors. The Hosmer-Lemeshow test was used to check the goodness-offit of the model. A $p$-value of 0.05 or less was considered as statistically significant. All analyses were performed using SPSS version 24.0 (IBM SPSS Statistics for Windows, 142 Armonk, NY: IBM Corporation).

\section{RESULTS}

Out of 803 patients, $41.09 \%$ were male and $58.91 \%$ were females. The mean age was reported as $48.34(9.4)$ years. The average number of medicines per encounter was 5.23 (2.8). More than five drugs were prescribed in almost $73.12 \%$ patients. The questionnaire showed good reliability with Cronbach's alpha coefficient value of 0.71 . The most frequent diagnosis was diabetes mellitus (38.27\%), followed by myocardial infarction (28.78\%), peripheral vascular disease (22.54\%), peptic ulcer disease $(21.23 \%)$, liver disease $(17.32 \%)$, congestive heart failure (13.43\%), COPD (11.23\%), hemiplegia (9.23\%), moderate to severe chronic kidney disease (9.2\%), connective tissue disease (6.3\%), cerebrovascular disease (6.2\%), dementia (3.9\%), solid tumor (2.3\%), malignant lymphoma (1.2\%), and leukemia $(0.12 \%)$. The demographic and clinical data of patients are shown in Table 1. Different errors found in the prescribing were inappropriate dose (39.75\%), invalid indication (43.17\%), multiple drugs for the same condition (39.3\%), longer duration of drug therapy than recommended (12.6\%), and drug-drug interactions (DDIs) (43.58\%). Overall, 38.25\% of prescriptions showed one or two and $17.23 \%$ prescriptions showed three or more than three drug-drug interaction regardless of severity. Among drug-drug interactions, $4.13 \%$ were contraindicated, $22.8 \%$ were severe, $53.42 \%$ were moderate, and $19.8 \%$ were minor. The medication errors in the prescription are presented in Table 2.

\section{Risk Factors of Medication Errors in Patients Suffering From Chronic Diseases}

Independent variables showing a significant relationship with medication errors in univariate analysis $(p<0.1)$ were added in the multiple logistics regression. The odds ratio (OR), 95\% confidence intervals, and $p$-value for the independent variables included in the multiple logistic regression are presented in Table 3. A greater risk for the occurrence of medication errors was associated with age $\geq 60$ years $(\mathrm{OR}=1.9 ; 95 \% \mathrm{CI}=1.3$ $3.1 ; p=0.001)$, overburdened healthcare system $(\geq 20$ patients in $1 \mathrm{~h}$; $\mathrm{OR}=2.2 ; 95 \% \mathrm{CI}=1.64-3.56 ; p<0.000$ ), number of prescribed drugs $\geq 5(\mathrm{OR}=1.74 ; 95 \% \mathrm{CI}=1.02-2.64 ; p<0.000)$, number of comorbidities $(\mathrm{OR}=2.6$; $95 \% \mathrm{CI}=1.72-3.6 ; p=$ $0.003)$, CCI score ( $\mathrm{OR}=1.31 ; 95 \% \mathrm{CI}=0.49-1.84 ; p=0.004)$, multiple prescribers to one patient $(\mathrm{OR}=1.12 ; 95 \% \mathrm{CI}=0.64-$ $1.76 ; p=0.001)$, and trainee practitioner $(\mathrm{OR}=1.03 ; 95 \% \mathrm{CI}=$ $0.61-1.65 ; p=0.003)$.

The association was not significant with the patients' gender $(\mathrm{OR}=0.72 ; 95 \% \mathrm{CI}=0.52-1.21 ; p=0.7)$, prescription by a specialist $(\mathrm{OR}=0.27 ; 95 \% \mathrm{CI}=0.03-0.47 ; p=0.4)$, presence of previous medical record $(\mathrm{OR}=0.63 ; 95 \% \mathrm{CI}=0.17-1.34 ; p$ $=0.09)$, use of online software in prescription generation $(\mathrm{OR}=$ $0.69 ; 95 \% \mathrm{CI}=0.23-1.39 ; p=0.1$ ), and review of prescription by a clinical pharmacist $(\mathrm{OR}=0.28 ; 95 \% \mathrm{CI}=0.03-0.59 ; p=0.7)$.

The logistic regression model showed an accuracy of $64.73 \%$. The logistic regression model showed good model fit, as demonstrated by the non-significant difference $(p=0.914)$ between observed and predicted probabilities in the HosmerLemeshow test and a significant difference $(p<0.001)$ between observed and predicted probabilities in the goodness of fit model test. 
TABLE 1 | Demographic and clinical characteristics of the patients included in the study $(N=803)$.

\begin{tabular}{|c|c|}
\hline Variables & Results \\
\hline Gender, male & $41.09 \%(330)$ \\
\hline Mean age & $48.34 \pm 9.4$ \\
\hline Patients age $\geq 60$ years & $36.98 \%(297)$ \\
\hline Mean number of prescribed drugs & $5.23(2.8)$ \\
\hline Patients prescribed with five or more drugs & $73.12 \%$ \\
\hline Mean number of physicians who prescribed to single patient & $1.67 \pm 0.73$ \\
\hline Mean number of diseases per patient & $1.8 \pm 0.81$ \\
\hline Patients with more than two diseases & $44.20 \%(355)$ \\
\hline $\mathrm{CCl}$ & $1.73 \pm 2.44$ \\
\hline \multicolumn{2}{|l|}{ Diagnosis } \\
\hline Diabetes mellitus & $38.27 \%$ \\
\hline Moderate to severe CKD & $9.2 \%$ \\
\hline Connective tissue disease & $6.3 \%$ \\
\hline COPD & $11.23 \%$ \\
\hline Liver disease & $17.32 \%$ \\
\hline Peripheral vascular disease & $22.54 \%$ \\
\hline Myocardial infarction & $28.78 \%$ \\
\hline Congestive heart failure & $13.43 \%$ \\
\hline Cerebrovascular disease & $6.2 \%$ \\
\hline Hemiplegia & $9.23 \%$ \\
\hline Peptic ulcer disease & $21.23 \%$ \\
\hline Dementia & $3.9 \%$ \\
\hline Leukemia & $0.12 \%$ \\
\hline Malignant lymphoma & $1.2 \%$ \\
\hline Solid tumor & $2.3 \%$ \\
\hline AIDS & - \\
\hline
\end{tabular}

Data are presented as mean \pm standard deviation and percentage (number) unless otherwise stated.

COPD, chronic obstructive pulmonary disease; CCl, Charlson comorbidity index; CKD, chronic kidney disease; AIDS, acquired immunodeficiency syndrome.

\section{DISCUSSION}

Medication errors result in increasing burden on the healthcare system. The factors associated with medication errors were studied in different hospitals of South Punjab, Pakistan. Consistent with previous literature, older age, overburdened healthcare system, higher number of prescribed drugs, and comorbidities were significantly associated with an increase in the risk of medication errors $(21,36,37)$. The number of medicines in the prescription was the most significant risk factor for inappropriate prescribing. Polypharmacy was considered as the utilization of five or more drugs. WHO recommends a maximum of three drugs in a prescription as optimal therapy (38). More than five drugs were prescribed to a lot of number of patients. It is a well-recognized risk factor for medication errors $(8,36,39)$. The risk of error increased from 17 to $66 \%$ with the increase in the number of drugs in a prescription from two to 16 (40). Polypharmacy requires special attention. Potentially inappropriate drugs should be identified, and drugs with narrow therapeutic ranges or associated with frequent adverse drug
TABLE 2 | Prevalence of medication errors in chronic disease patients.

\begin{tabular}{lc}
\hline Medication errors & Percentage \\
\hline Inappropriate dose & $39.75 \%$ \\
Invalid indication & $43.17 \%$ \\
Multiple drugs for same condition & $39.3 \%$ \\
Too short dosing frequency & $28.1 \%$ \\
Longer duration of drug therapy than recommended & $12.6 \%$ \\
Drug-drug interactions (DDI) & \\
Overall DDI & $43.58 \%$ \\
Minor DDI & $19.8 \%$ \\
Moderate DDI & $53.42 \%$ \\
Severe DDI & $22.8 \%$ \\
Contraindicated DDI & $4.13 \%$ \\
Mean drug-drug interactions per patient & \\
Minor DDI & $0.41 \pm 0.3$ \\
Moderate DDI & $1.87 \pm 2.03$ \\
Severe DDI & $1.36 \pm 1.96$ \\
Contraindicated DDI & $0.14 \pm .39$ \\
Presence of one to two DDI & $38.25 \%$ \\
\hline & $17.23 \%$ \\
\hline & \\
\hline
\end{tabular}

Overall prevalence, presence of at least one DDI regardless of type and severity. Percentages may not add up to overall prevalence as many patients were having more than one DDI.

reactions should be avoided if possible and carefully monitored when used.

Comorbidities were associated with an increased risk of medication errors. Comorbidities increase the interaction of patients with healthcare professionals, and patients use more medicines for a longer duration (21). Comorbidities were associated with the increase in the risk of medication errors. In a country like Pakistan, a complete electronic medical record of a patient is not available. Patients visit to different healthcare professionals for different comorbidities. This causes confusion and lack of medical records from one prescriber, resulting in medication error from other prescribers due to a lack of knowledge of the medication history (21). Workload was also significantly associated with an increase in the risk of medication errors. Overburden and fatigue can affect the efficiency of health professionals. Reducing the workload may have positive effects in avoiding medication errors. A study showed that reducing the workload on a physician was positively associated to avoiding the risk of medication errors (41).

It was observed that prescription from a specialist and review of a prescription by a consultant can reduce the chances of medication errors. This may be due to the fact that healthcare professionals are usually more familiar with the errors related to the drugs they more frequently prescribe. Specialists mostly prescribe drugs of specific categories, so they are more aware of them, and the chances of error decrease. Moreover, senior physicians learn a lot from their experience, so the chances of error reduced with the experience. Our findings are in line with the previous literature. Hussain et al., in their study, found that prescription from practitioners who had seen the patients 
TABLE 3 | Multiple logistic regression analysis for risk factors associated with medication errors in chronic disease patients.

\begin{tabular}{|c|c|c|c|}
\hline Variables & OR & $95 \% \mathrm{Cl}$ & $p$-value \\
\hline Gender, male & 0.72 & $0.52-1.21$ & 0.7 \\
\hline Age $\geq 60$ years & 1.9 & $1.3-3.1$ & 0.001 \\
\hline Number of prescribed drugs $\geq 5$ & 1.74 & $1.02-2.64$ & 0.000 \\
\hline Overburden & 2.2 & $1.64-3.56$ & 0.000 \\
\hline Comorbidities & 2.6 & $1.72-3.6$ & 0.003 \\
\hline CCl score & 1.31 & $0.49-1.84$ & 0.004 \\
\hline Multiple prescribers to one patient & 1.12 & $0.64-1.76$ & 0.001 \\
\hline Trainee practitioner & 1.03 & $0.61-1.65$ & 0.003 \\
\hline Prescription by a specialist & 0.27 & $0.03-0.47$ & 0.4 \\
\hline Presence of previous medical record & 0.63 & $0.17-1.34$ & 0.09 \\
\hline $\begin{array}{l}\text { Use of online software in prescription } \\
\text { generation }\end{array}$ & 0.69 & $0.23-1.39$ & 0.1 \\
\hline $\begin{array}{l}\text { Review of prescription by a clinical } \\
\text { pharmacist }\end{array}$ & 0.28 & $0.03-0.59$ & 0.7 \\
\hline Private hospitals & 1.24 & $1.01-1.52$ & 0.039 \\
\hline
\end{tabular}

OR, odds ratio; CCl, Charlson comorbidity index; Overburden, $\geq 20$ patients in $1 \mathrm{~h}$. A p-value of 0.05 or less was considered as statistically significant.

with potential DDIs before contained less errors and DDIs (42). Results of another study showed that prescriptions from a specialist contained less DDIs than prescriptions from general practitioners (43). Regular training of the junior medical staff can reduce the rate of potential medical errors. Training and feedback control of prescribing by senior doctors should be associated with the availability of online references for immediate identification and verification of potential prescribing faults (44). Moreover, the choice of treatment should generally be in line with approved guidelines, although flexibility may be necessary in individual cases (45). Prescription must be reviewed by a senior healthcare professional to remove medical errors that may be mistaken by the prescriber.

The review of prescription by a clinical pharmacist also reduced the risk of errors. The importance of a clinical pharmacist on the healthcare system is well-recognized, but unfortunately in Pakistan, the role of a clinical pharmacist is not well-established. Most of the basic healthcare units and private hospitals do not have a pharmacist. In teaching hospitals, pharmacists are working on administrative posts instead of in clinical practice. Literature shows that the involvement of a clinical pharmacist in a health system reduces the risk of errors, increases adherence to therapy, and supports physicians to manage drug-related events $(46,47)$. Another study demonstrated that most of the drug-related events identified by clinical pharmacists were not detected in routine clinical practice (48).

The association was also not significant with the use of online software programs in prescription generation. The manual procedure for prescription generation is associated with a greater risk of medication errors. Healthcare professionals have to know about a large number of potential DDIs and their adverse effects. Continuous progression in medical education requires continuous learning. The use of information technology (IT) can overcome this issue. IT can be used to learn about potential drug-related events, to check a prescription for potential DDIs, and to get access to a patient's medical records (49). A previous study demonstrated that healthcare professionals who rely on personal digital assistance and computerized alert system to check medication-related errors were less prone to inappropriate prescribing (50). A study showed that the use of computer software programs during the prescribing process reduced the chances of error up to $66 \%$ in general physicians (51). Ansari and Neupane compared the manual and the computer-generated prescriptions in hospitals of Nepal. Hospitals wherein the online drug interaction system was installed were less prone to medication errors (52).

Due to the increasing cost of healthcare services, there is an urgent need to consider medication errors in routine clinical practice to reduce the burden on the healthcare system. Reduction of complexity in the act of prescribing by the introduction of automation improves a prescriber's knowledge by education, use of online aid, feedback control systems, and monitoring of the effects of interventions that can help in the reduction of medication errors. Most of the medication errors are preventable; medication review of the prescriptions by an experienced healthcare professional can detect these errors, and reconciliation can help remove such errors before these reach the patient.

This study is the first to investigate the risk factors for medication errors in chronic disease patients visiting as outpatients for regular follow-up. Currently, there is no system in South Punjab to report medication errors. Therefore, policy makers and healthcare providers are encouraged to develop and implement medication error reporting forms. Despite several strengths, few limitations should be kept in mind before interpretation of the results. This study was conducted in a specific population (patients suffering from chronic diseases), so its results should be generalized with caution, but it can be assumed that the results found in this study can be generalized to chronic disease patients. Moreover, the frequency of potential medication errors was assessed, but their impact on other outcomes like outpatient visits, hospital admissions, and quality of life was not assessed. In a detailed study, the impact of medication errors on patient-relevant endpoints such as health status, quality of life, and hospital admissions should be assessed.

\section{CONCLUSION}

A greater risk for the occurrence of medication errors was associated with older age, overburdened healthcare system $(\geq 20$ patients in $1 \mathrm{~h}$ ), higher number of drugs in a prescription, comorbidities, multiple prescribers to one patient, and trainee practitioner. The risk was not significantly associated with a patient's gender, prescription by a specialist, presence of previous 
medical record, use of online software in prescription generation, and review of prescription by a clinical pharmacist.

\section{IMPLICATIONS FOR POLICY AND PRACTICE}

Due to the increasing cost of healthcare services, there is an urgent need to consider medication errors in routine clinical practice to reduce the burden on the healthcare system. Reduction of complexity in the act of prescribing by the introduction of automation, improving the prescriber's knowledge by education, use of online aid and feedback control systems, and monitoring the effects of interventions can help in the reduction of medication errors.

Knowledge about the risk factors of potential drug-drug interactions and designing and implementing strategies to control them can reduce the economic and humanistic burden due to drug-related events.

\section{DATA AVAILABILITY STATEMENT}

The datasets generated for this study are available on request to the corresponding author.

\section{REFERENCES}

1. O'Connor MN, Gallagher P, O'Mahony D. Inappropriate prescribing. Drugs Aging. (2012) 29:437-52. doi: 10.2165/11632610-000000000-00000

2. Cohen MR. Medication Errors: Causes, Prevention, Risk Management. Washington, DC: Jones \& Bartlett Learning (1999).

3. Moura CS, Acurcio FA, Belo NO. Drug-drug interactions associated with length of stay and cost of hospitalization. J Pharm Pharm Sci. (2009) 12:26672. doi: $10.18433 / \mathrm{J} 35 \mathrm{C} 7 \mathrm{Z}$

4. FHCC. Empowering Employers to Transform Healthcare Quality and Delivery. Florida Health Care Coalition (2018). Available online at: http://www.flhcc. $\mathrm{com} /$ (accessed November 17, 2018).

5. NCCMERP. About Medication Errors. National Coordinating Council for Medication Error Reporting and Prevention (2015). Available online at: https://www.nccmerp.org/about-medication-errors (accessed November 17, 2018).

6. Da Silva BA, Krishnamurthy M. The alarming reality of medication error: a patient case and review of Pennsylvania and National data. J Commun Hosp Int Med Perspect. (2016) 6:31758. doi: 10.3402/jchimp.v6.31758

7. Al Hamid A, Ghaleb M, Aljadhey H, Aslanpour Z. A systematic review of hospitalization resulting from medicine-related problems in adult patients. $\mathrm{Br}$ J Clin Pharmacol. (2014) 78:202-17. doi: 10.1111/bcp.12293

8. Janković SM, Pejčić AV, Milosavljević MN, Opančina VD, Pešić NV, Nedeljković TT, et al. Risk factors for potential drug-drug interactions in intensive care unit patients. J Crit Care. (2018) 43:1-6. doi: 10.1016/j.jcrc.2017.08.021

9. Westerlund T, Marklund B. Assessment of the clinical and economic outcomes of pharmacy interventions in drug-related problems. J Clin Pharma Ther. (2009) 34:319-27. doi: 10.1111/j.1365-2710.2008.01 017.x

10. Smith J, Cavell G. Building a safer NHS for patients: improving medication safety. (2004).

11. Lynskey D, Haigh S, Patel N, Macadam A. Medication errors in community pharmacy: an investigation into the types and potential causes. Int $J$ Pharm Pract. (2007) 15:105-12. doi: 10.1211/ijpp.15.2.0005

12. Espinosa-Bosch M, Santos-Ramos B, Gil-Navarro MV, SantosRubio MD, Marín-Gil R, Villacorta-Linaza P. Prevalence of drug

\section{ETHICS STATEMENT}

The study protocol was approved by the Research and Ethics committee of Faculty of Pharmacy Bahauddin Zakariya University and the concerned hospitals (registration no. Bzbp18-4207). The patients/participants provided their written informed consent to participate in this study.

\section{AUTHOR CONTRIBUTIONS}

MR, AR, II, SA, IK, SShah, GA, SShak, MA, and KH made substantial contributions to the conception and design of the study and the analysis and interpretation of the data. MR and AR made substantial contributions to the analysis and interpretation of the data. All the authors drafted the work or revised it critically for important intellectual content, reviewed, critiqued, and approved the final version submitted for publication.

\section{ACKNOWLEDGMENTS}

The authors are very grateful to the staff of all included hospitals, who supported us during the whole research period.

interactions in hospital healthcare. Int $J$ Clin Pharm. (2012) 34:807-17. doi: 10.1007/s11096-012-9697-0

13. Schuler J, Dückelmann C, Beindl W, Prinz E, Michalski T, Pichler M. Polypharmacy and inappropriate prescribing in elderly internalmedicine patients in Austria. Wien Klin Wochenschr. (2008) 120:73341. doi: 10.1007/s00508-008-1089-z

14. Chatsisvili A, Sapounidis I, Pavlidou G, Zoumpouridou E, Karakousis VA, Spanakis $M$, et al. Potential drug-drug interactions in prescriptions dispensed in community pharmacies in Greece. Pharm World Sci. (2010) 32:187-93. doi: 10.1007/s11096-010-9365-1

15. Kovačević M, Vezmar Kovačević S, Miljković B, Radovanović S, Stevanović P. The prevalence and preventability of potentially relevant drug-drug interactions in patients admitted for cardiovascular diseases: a cross-sectional study. Int J Clin Pract. (2017) 71:e13005. doi: 10.1111/ijcp.13005

16. Avery AA, Barber N, Ghaleb M, Dean Franklin B, Armstrong S, Crowe S, et al. Investigating the Prevalence and Causes of Prescribing Errors in General Practice: the Practice Study. General Medical Council (2012).

17. Leone R, Magro L, Moretti U, Cutroneo P, Moschini M, Motola D, et al. Identifying adverse drug reactions associated with drug-drug interactions. Drug Saf. (2010) 33:667-75. doi: 10.2165/11534400-000000000-00000

18. Rehman Au, Hassali MAA, Muhammad SA, Harun SN, Shah S, Abbas S. The economic burden of chronic obstructive pulmonary disease (COPD) in Europe: results from a systematic review of the literature. Eur J Health Econ. (2020) 21:181-94. doi: 10.1007/s10198-019-01119-1

19. ur Rehman A, Ahmad Hassali MA, Muhammad SA, Shah S, Abbas $\mathrm{S}$, Hyder Ali IAB, et al. The economic burden of chronic obstructive pulmonary disease (COPD) in USA, Europe and Asia: results from a systematic review of the literature. Expert Rev Pharmacoecon Outcomes Res. (2019). doi: 10.1080/14737167.2020.1678385. [Epub ahead of print].

20. Rehman U, Hassali M, Muhammad S, Shakeel S, Chin O, Ali I, et al. Economic burden of chronic obstructive pulmonary disease patients in Malaysia: a longitudinal study. Pharmacoecon Open. (2020). doi: 10.1007/s41669-020-00214-x. [Epub ahead of print].

21. Busa G, Burlina A, Damuzzo V, Chiumente M, Palazzo AC. Comorbidity, polytherapy, and drug interactions in a neurological context: an example of a multidisciplinary approach to promote the rational use of drugs. J Pharm Pract. (2018) 31:58-65. doi: 10.1177/0897190017699138 
22. Roblek T, Trobec K, Mrhar A, Lainscak M. Potential drug-drug interactions in hospitalized patients with chronic heart failure and chronic obstructive pulmonary disease. Arch Med Sci. (2014) 10:920-32. doi: 10.5114/aoms.2014.46212

23. WHO. Essential Medicines and Health Products; The World Medicines Situation Report. World Health Organisation (2018). Available online at: https://www.who.int/medicines/areas/policy/world_medicines_situation/ en/ (accessed February 24, 2019).

24. Haider S, Johnell K, Thorslund M, Fastbom J. Trends in polypharmacy and potential drug-drug interactions across educational groups in elderly patients in Sweden for the period 1992-2002. Int J Clin Pharm Ther. (2007) 45:643-53. doi: 10.5414/CPP45643

25. Bjerrum L, Gonzalez Lopez-Valcarcel B, Petersen G. Risk factors for potential drug interactions in general practice. Eur J Gen Pract. (2008) 14:239. doi: 10.1080/13814780701815116

26. Cruciol-Souza JM, Thomson JC. Prevalence of potential drug-drug interactions and its associated factors in a Brazilian Teaching Hospital. J Pharm Pharm Sci. (2006) 9:427-33.

27. Saedder EA, Lisby M, Nielsen LP, Bonnerup DK, Brock B. Number of drugs most frequently found to be independent risk factors for serious adverse reactions: a systematic literature review. Br J Clin Pharmacol. (2015) 80:80817. doi: $10.1111 /$ bcp. 12600

28. Milosavljevic MN, Kočovic AG, Jankovic SM, Radovanovic DM, Milisavljevic SS, Stefanovic SM. Risk factors for the occurrence of potential drug-drug interactions in surgical patients. Serbian J Exp Clin Res. (2019). doi: 10.2478/sjecr-2019-0032. [Epub ahead of print].

29. Aronson JK. Medication errors: definitions and classification. Br J Clin Pharmacol. (2009) 67:599-604. doi: 10.1111/j.1365-2125.2009.03415.x

30. Fried TR, O'Leary J, Towle V, Goldstein MK, Trentalange M, Martin DK. Health outcomes associated with polypharmacy in community-dwelling older adults: a systematic review. J Am Geriatr Soc. (2014) 62:226172. doi: 10.1111 /jgs. 13153

31. Charlson M, Szatrowski TP, Peterson J, Gold J. Validation of a combined comorbidity index. J Clin Epidemiol. (1994) 47:1245-51. doi: 10.1016/0895-4356(94)90129-5

32. World health Organization. Health Information Systems. (2010) Available online at: www.who.int/healthinfo/systems/WHO_MBHSS_2010_section3_ web.pdf (accessed September 9, 2020).

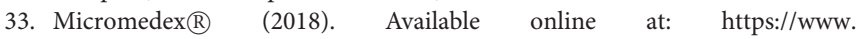
micromedexsolutions.com/ (accessed October 10, 2018).

34. Morimoto T, Gandhi T, Seger A, Hsieh T, Bates D. Adverse drug events and medication errors: detection and classification methods. BMJ Qual Saf. (2004) 13:306-14. doi: 10.1136/qshc.2004.010611

35. ur Rehman A, Ahmad Hassali MA, Harun SN, Abbas S, Muneswarao J, Ali $\mathrm{IABH}$, et al. Validation and clinical interpretation of the St George's respiratory questionnaire for COPD (SGRQ-C) after adaptation to Malaysian language and culture, in patients with COPD. Health Qual Life Outcomes. (2020) 18:138. doi: 10.1186/s12955-020-01393-1

36. Janchawee B, Wongpoowarak W, Owatranporn T, Chongsuvivatwong V. Pharmacoepidemiologic study of potential drug interactions in outpatients of a university hospital in Thailand. J Clin Pharm Ther. (2005) 30:1320. doi: 10.1111/j.1365-2710.2004.00598.x

37. Rosas-Carrasco Ó, García-Peña C, Sánchez-García S, Vargas-Alarcón G, Gutiérrez-Robledo LM, Juárez-Cedillo T. The relationship between potential drug-drug interactions and mortality rate of elderly hospitalized patients. Rev Invest Clín. (2011) 63:564-73.

38. World Health Organization. Guide to Good Prescribing - A Practical Manual. (2018) Available online at: http://www.who.int/medicines/areas/rational_use/ en/ (accessed October 10, 2018).

39. Lim LM, McStea M, Chung WW, Azmi NN, Aziz SAA, Alwi S, et al. Prevalence, risk factors and health outcomes associated with polypharmacy among urban community-dwelling older adults in multi-ethnic Malaysia. PLoS ONE. (2017) 12:e0173466. doi: 10.1371/journal.pone.0173466
40. Weideman RA, Bernstein IH, McKinney WP. Pharmacist recognition of potential drug interactions. Am J Health Syst Pharm. (1999) 56:15249. doi: 10.1093/ajhp/56.15.1524

41. Galt KA, Rule AM, Clark BE, Bramble JD, Taylor W, Moores KG. Best Practices in Medication Safety: Areas for Improvement in the Primary Care Physician's Office. Creighton Univ Omaha $\mathrm{Ne}$ (2005).

42. Hussain R, Hassali MA, Ur Rehman A, Muneswarao J, Hashmi F. Physicians' understanding and practices of pharmacovigilance: qualitative experience from a lower middle-income country. Int J Environ Res Public Health. (2020) 17:2209. doi: 10.3390/ijerph17072209

43. Lowe CJ, Raynor DK, Purvis J, Farrin A, Hudson J. Effects of a medicine review and education programme for older people in general practice. $\mathrm{Br} J$ Clin Pharmacol. (2000) 50:172-5. doi: 10.1046/j.1365-2125.2000.00247.x

44. Scheife RT, Hines LE, Boyce RD, Chung SP, Momper JD, Sommer CD, et al. Consensus recommendations for systematic evaluation of drug-drug interaction evidence for clinical decision support. Drug Saf. (2015) 38:197206. doi: 10.1007/s40264-014-0262-8

45. ur Rehman A, Hassali MAA, Abbas S, Ali IABH, Harun SN, Muneswarao J, et al. Pharmacological and non-pharmacological management of COPD; limitations and future prospects: a review of current literature. J Public Health. (2019) 28:357-66. doi: 10.1007/s10389-019-01021-3

46. Hasan SS, Lim KN, Anwar M, Belagodu Sridhar S, Ahmadi K, Yuan AWL, et al. Impact of pharmacists' intervention on identification and management of drug-drug interactions in an intensive care setting. Singapore Med J. (2012) 53:526-31.

47. Zaal RJ, Jansen MM, Duisenberg-van Essenberg M, Tijssen CC, Roukema JA, van den Bemt PM. Identification of drug-related problems by a clinical pharmacist in addition to computerized alerts. Int J Clin Pharm. (2013) 35:753-62. doi: 10.1007/s11096-013-9798-4

48. Guignard B, Bonnabry P, Perrier A, Dayer P, Desmeules J, Samer CF. Drug-related problems identification in general internal medicine: the impact and role of the clinical pharmacist and pharmacologist. Eur J Int Med. (2015) 26:399-406. doi: 10.1016/j.ejim.2015.0 5.012

49. ur Rehman A, Naeem F, Abbas S, Ashfaq F, Hassali MAA. Utilization of short message service (SMS) in non-pharmacological management of hypertension. A pilot study in an URBAN Public Hospital of Multan, Pakistan. J Public Health. (2019) 27:561-7. doi: 10.1007/s10389-018-0 982-9

50. Roblek T, Vaupotic T, Mrhar A, Lainscak M. Drug-drug interaction software in clinical practice: a systematic review. Eur J Clin Pharmacol. (2015) 71:13142. doi: 10.1007/s00228-014-1786-7

51. Lainer M, Mann E, Sönnichsen A. Information technology interventions to improve medication safety in primary care: a systematic review. Int J Qual Health Care. (2013) 25:590-8. doi: 10.1093/intqhc/mzt043

52. Ansari M, Neupane D. Study on determination of errors in prescription writing: a semi-electronic perspective. Kathmandu Univ Med J. (2009) 7:23841. doi: 10.3126/kumj.v7i3.2730

53. Ko Y, Malone DC, D'Agostino JV, Skrepnek GH, Armstrong EP, Brown M, et al. Potential determinants of prescribers' drug-drug interaction knowledge. Res Soc Adm Pharm. (2008) 4:355-66. doi: 10.1016/j.sapharm.2007.10.004

Conflict of Interest: The authors declare that the research was conducted in the absence of any commercial or financial relationships that could be construed as a potential conflict of interest.

Copyright (c) 2020 Rasool, Rehman, Imran, Abbas, Shah, Abbas, Khan, Shakeel, Ahmad Hassali and Hayat. This is an open-access article distributed under the terms of the Creative Commons Attribution License (CC BY). The use, distribution or reproduction in other forums is permitted, provided the original author(s) and the copyright owner(s) are credited and that the original publication in this journal is cited, in accordance with accepted academic practice. No use, distribution or reproduction is permitted which does not comply with these terms. 